\title{
Treatment of Severe Aortic Stenosis
}

\section{Wilbert S Aronow*}

Department of Medicine, Division of Cardiology, Westchester Medical Center/New York Medical College, Valhalla, NY, USA

Severe valvular aortic stenosis (AS) is an aortic valve area of less than $1.0 \mathrm{~cm}^{2}$. Angina pectoris, syncope or near syncope, and congestive heart failure (CHF) are the 3 classic manifestations of severe AS. Patients with symptomatic severe valvular AS have a poor prognosis [1-4]. Ross and Braunwald found that the average survival rate was 3 years after the onset of angina pectoris in patients with severe AS [2]. Ross and Braunwald reported that the average survival rate after the onset of syncope in patients with severe AS was 3 years. Ross and Braunwald showed that the average survival rate after the onset of $\mathrm{CHF}$ in patients with severe AS was 1.5 to 2 years. In a prospective study, at 19-month follow-up (range 2 to 36 months), $90 \%$ of 30 patients with $\mathrm{CHF}$ associated with unoperated severe AS and a normal left ventricular ejection fraction (LVEF) were dead [5]. At 13-month follow-up (range 2 to 24 months), $100 \%$ of 18 patients with $\mathrm{CHF}$ associated with unoperated severe AS and an abnormal LVEF were dead [5]. At 20-month follow-up of 40 elderly patients with severe AS, CHF, syncope or angina, pectoris was present in 36 of 37 patients (97\%) who developed new coronary events and in none of 3 patients (0\%) without new coronary events [1].

Prophylactic antibiotics are not recommended to prevent bacterial endocarditis in patients with AS [6]. Patients with CHF, exertional syncope, or angina pectoris associated with severe AS should undergo aortic valve replacement (AVR) promptly. Valvular surgery is the only definitive therapy in these patients [7]. Medical therapy does not relieve the mechanical obstruction to left ventricular outflow and does not relieve symptoms or progression of the disorder.

American College of Cardiology (ACC)/American Heart Association (AHA) class I indications for AVR in patients with severe AS are 1) symptoms, 2) undergoing coronary artery bypass surgery, 3) undergoing surgery on the aorta or other heart valves, and 4) a LVEF less than 50\% [7]. Although the ACC/AHA guidelines do not recommend AVR in patients with asymptomatic severe AS and normal LVEF, there are data suggesting otherwise [8-12]. Pai et al. found in their database that 99 of 338 patients (29\%), mean age 71 years, with asymptomatic severe AS had AVR during 3.5-year follow-up. Survival at 1, 2, and 5 years was $67 \%, 56 \%$, and $38 \%$, respectively for nonoperated patients and $94 \%, 93 \%$, and $90 \%$, respectively for those who had AVR [8]. In the unoperated group, beta blocker use significantly reduced mortality by $48 \%$, and statin use significantly reduced mortality by $48 \%$.

Severe asymptomatic AS was present in 622 patients, mean age 72 years, at the Mayo Clinic [9]. Of the 622 patients, 166 (27\%) developed symptoms and had AVR. Another 97 patients (16\%) had AVR in the absence of symptoms. At 3-year follow-up, 52\% of the 622 patients had developing symptoms, undergone AVR, or died. The most important risk factor for 10-year mortality was absence of AVR (hazard ratio $=3.53, \mathrm{p}<0.001$ ).

Of 197 consecutive patients with asymptomatic severe AS, early AVR was performed in 102 patients (52\%) [10]. The estimated actuarial 6-year all-cause mortality rates were $2 \%$ for AVR and $32 \%$ for the conventional treatment group $(\mathrm{p}<0.001)$. Despite being asymptomatic, patients with very severe AS have a poor prognosis [11]. Early elective AVR should be considered in these patients.
Of 73 patients with severe AS who did not undergo AVR, 15 (14\%) died at 15-month follow-up [12]. Of these 73 patients, symptoms were thought to be unrelated to the AS in 31 patients. Exercise stress tests for symptoms were performed in only $4 \%$ of the 42 asymptomatic patients.

Asymptomatic patients with low-gradient severe AS and normal LVEF with reduced stroke volume index had at 46-month follow-up aortic valve events similar to those with normal stroke volume index [13]. Of 248 patients with severe AS and a normal LVEF, 94 had a lowgradient ( $<30 \mathrm{~mm} \mathrm{Hg}$ mean gradient) (group 1), 87 had a moderate gradient (30-40 mm Hg mean gradient) (group 2), and 67 had a severe gradient ( $>40 \mathrm{~mm} \mathrm{Hg}$ mean gradient) (group 3) [14]. Symptoms were present in $49 \%$ of group 1 patients, in $55 \%$ of group 2 patients, and in $60 \%$ of group 3 patients (p not significant). At 45-60-month follow-up, the incidence of AVR or death was $71 \%$ for group 1,77\% for group 2, and $76 \%$ for group 3 (p value not significant). Kaplan-Meier survival curves for time to death in all 3 groups were significantly better for patients with AVR versus no AVR [14]. E/ $\mathrm{E}_{\text {lateral }}^{1}$ was an independent predictor of time to death in patients who did not receive AVR [15].

Percutaneous heart valve implantation may be performed in nonsurgical patients with end-stage calcific AS. In the Placement of Aortic Transcatheter Valves (PARTNER) trial, 699 high-risk patients with severe AS, mean age 84 years, were randomized to AVR or (transcatheter aortic valve replacement) TAVR [16]. All-cause mortality was $3.4 \%$ for the TAVR group versus $6.5 \%$ for the AVR group at 30 days (p value not significant) and $24.2 \%$ for the TAVR group versus $26.8 \%$ for the AVR group at 1 year ( $\mathrm{p}$ value not significant). Major stroke was 3.8\% for the TAVR group versus $2.1 \%$ for the AVR group at 30 days ( $\mathrm{p}$ value not significant) and $5.1 \%$ for the TAVR group versus $2.4 \%$ for the AVR group at 1 year ( $\mathrm{p}$ value not significant). Major vascular complications at 30 days were $11.0 \%$ for the TAVR group versus $3.2 \%$ for the AVR group $(\mathrm{p}<0.001)$. At 1 -year, there were similar improvements in cardiac symptoms for both groups. In the PARTNER trial, among inoperable patients with severe AS, compared with standard care, TAVR caused significant improvements in health-related quality of life maintained for at least 1 year [17].

On the basis of the available data, AVR should be performed in operable patients with severe AS. However, TAVR should be performed in non-operable patients with symptomatic severe AS to improve survival and quality of life compared with medical management.

The 2012 expert consensus document on TAVR recommends

*Corresponding author: Wilbert S Aronow, MD, FACC, FAHA, Professor of Medicine, Cardiology Division, New York Medical College, Macy Pavilion, Room 138, Valhalla, NY 10595, USA, Tel: (914) 493-5311; Fax: (914) 235-6274; E-mail: wsaronow@aol.com

Received December 10, 2012; Accepted December 14, 2012; Published December 17, 2012

Citation: Aronow WS (2013) Treatment of Severe Aortic Stenosis. J Cardiovasc Dis Diagn 1: e101. doi:10.4172/2329-9517.1000e101

Copyright: (c) 2013 Aronow WS. This is an open-access article distributed under the terms of the Creative Commons Attribution License, which permits unrestricted use, distribution, and reproduction in any medium, provided the original author and source are credited. 
TAVR in patients with severe, symptomatic calcific stenosis of a trileaflet aortic valve who have aortic and vascular anatomy suitable for TAVR and a predicted survival of more than 1 year, and who have a prohibitive surgical risk with an estimated $50 \%$ or greater mortality or irreversible morbidity at 30 days or other factors such as frailty, prior radiation therapy, porcelain aorta, and severe hepatic or pulmonary disease [18]. TAVR is a reasonable alternative to surgical AVR in patients at high surgical risk (PARTNER Trial Criteria STS $\geq 8 \%$ ) [18].

\section{References}

1. Aronow WS, Ahn C, Shirani J, Kronzon I (1998) Comparison of frequency of new coronary events in older persons with mild, moderate, and severe valvular aortic stenosis with those without aortic stenosis. Am J Cardiol 81: 647-649.

2. Ross J Jr, Braunwald E (1968) Aortic stenosis. Circulation 37: 61-67.

3. Braunwald E (1990) On the natural history of severe aortic stenosis. J Am Coll Cardiol 15: 1018-1020.

4. Rapaport E (1975) Natural History of aortic and mitral valve disease. Am J Cardiol 35: 221-227.

5. Aronow WS, Ahn C, Kronzon I, Nanna M (1993) Prognosis of congestive heart failure in patients aged $>$ or $=62$ years with unoperated severe valvular aortic stenosis. Am J Cardiol 72: 846-848.

6. Nishimura RA, Carabello BA, Faxon DP, Freed MD, Lytle BW, et al. (2008) ACC/AHA 2008 guideline update on valvular heart disease: focused update on infective endocarditis: A Report of the American College of Cardiology/ American Heart Association Task Force on Practice Guidelines: Endorsed by the Society of Cardiovascular Anesthesiologists, Society for Cardiovascula Angiography and Interventions, and Society of Thoracic Surgeons. Circulation 118: 887-896.

7. Bonow RO, Carabello BA, Chatterjee K, Antonio C, David P. Faxon et al (2006) ACC/AHA 2006 practice guidelines for the management of patients with valvular heart disease: Executive Summary. A Report of the American College of Cardiology/American Heart Association task force on Practice Guidelines (Writing Committee to Revise the 1988 Guidelines for the Management of Patients With Valvular Heart Disease) Developed in collaboration with the Society of Cardiovascular Anesthesiologists. Endorsed by the Society for Cardiovascular Angiography and Interventions and the Society of Thoracic Surgeons. J Am Coll Cardiol 48: 598-675.
8. Pai RG, Kapoor N, Bansal RC, Varadarajan P (2006) Malignant natural history of asymptomatic severe aortic stenosis: benefit of aortic valve replacement Ann Thorac Surg 82: 2116-2122.

9. Brown ML, Pellikka PA, Schaff HV, Scott CG, Mullany CJ, et al. (2008) The benefits of early valve replacement in asymptomatic patients with severe aortic stenosis. J Thorac Cardiovasc Surg 135: 308-315.

10. Duk-Hyun Kang, Sung-Ji Park, Ji Hye Rim, Sung-Cheol Yun, Dae-Hee Kim, et al. (2010) Early surgery versus conventional treatment in asymptomatic very severe aortic stenosis. Circulation 121: 1502-1509.

11. Rosenhek R, Zilberszac R, Schemper M, Czerny M, Mundigler G, et al. (2010) Natural history of very severe aortic stenosis. Circulation 121: 151-156.

12. Freed BH, Sugeng L, Furlong K, Mor-Avi V, Raman J, et al. (2010) Reasons for nonadherence to guidelines for aortic valve replacement in patients with very severe aortic stenosis and potential solutions. Am J Cardiol 105: 1339-1342.

13. Nikolaus Jander, Jan Minners, Ingar Holme, Eva Gerdts, Kurt Boman, et al. (2011) Outcome of patients with low-gradient "severe" aortic stenosis and preserved ejection fraction. Circulation 123: 887-895.

14. Belkin RN, Khalique O, Aronow WS, Ahn C, Sharma M (2011) Outcomes and survival with aortic valve replacement compared with medical therapy in patients with low-, moderate-, and severe-gradient severe aortic stenosis and normal left ventricular ejection fraction. Echocardiography 28: 378-387.

15. Khalique O, Belkin RN, Li YW (2012) Diastolic function and survival in patients with severe aortic stenosis and normal left ventricular ejection fraction (abstract). J Am Coll Cardiol 59: A334-A335.

16. Smith CR, Leon MB, Mack MJ, Miller DC, Moses JW, et al. (2011) Transcatheter versus surgical aortic-valve replacement in high-risk patients. $\mathrm{N}$ engl $\mathrm{J}$ Med $364: 2187-2198$

17. Matthew R. Reynolds, Elizabeth A, Magnuson, Yang Lei, Martin B, et al. (2011) Health-related quality of life after transcatheter aortic valve replacement in inoperable patients with severe aortic stenosis. Circulation 124: 1964-1972.

18. Holmes DR Jr, Mack MJ, Kaul S, Agnihotri A, Alexander KP, et al. (2012) 2012 ACCF/AATS/SCAI/STS expert consensus document on transcatheter aortic valve replacement: Developed in collaboration with the American Heart Association, American Society of Echocardiography, European Association for Cardio-Thoracic Surgery, Heart Failure Society of America, Mended Hearts, Society of Cardiovascular Anesthesiologists, Society of Cardiovascular Computed Tomography, and Society for Cardiovascular Magnetic Resonance. Ann Thorac Surg 93: 1340-1395. 